\title{
Imaging and Analytical Approaches for Characterization of Soil Mineral Weathering
}

\author{
Alice Dohnalkova ${ }^{1}$, Bruce Arey ${ }^{2}$, Tamas Varga ${ }^{1}$, Micah Miller ${ }^{3}$ and Libor Kovarik ${ }^{1}$ \\ ${ }^{1}$ Environmental Molecular Sciences Laboratory, Pacific Northwest National Laboratory, Richland, WA, \\ USA \\ 2. Energy and Environmental Directorate, Pacific Northwest National Laboratory, Richland, WA, USA \\ 3. Physical Sciences Division, Pacific Northwest National Laboratory, Richland, WA, USA
}

Soil minerals weathering is the primary natural source of nutrients necessary to sustain productivity in terrestrial ecosystems. Soil microbial communities increase soil mineral weathering and mineral-derived nutrient availability through physical and chemical processes [1]. Rhizosphere, the zone immediately surrounding plant roots, is a biogeochemical hotspot with microbial activity, soil organic matter production, mineral weathering, and secondary phase formation all happening in a small temporally ephemeral zone of steep geochemical gradients. The detailed exploration of the micro-scale rhizosphere is essential to our better understanding of large-scale processes in soils, such as nutrient cycling, transport and fate of soil components, microbial-mineral interactions, soil erosion, soil organic matter turnover and its molecular-level characterization, and predictive modeling.

We employed the laboratory setup of column-grown mesocosms of Pinus resinosa, a widespread NorthAmerican pine forests ecosystem representative cultivated under previously demonstrated experimental conditions [2]. The tree seedlings were grown in well-defined soil mineral mix in controlled environment with minimal nutrients, and bacterial inoculum was added to develop microbial biofilms for mineral weathering. The designed mineral mix contained quartz $\mathrm{SiO} 2(95.5 \% \mathrm{w} / \mathrm{w})$, anorthite $\mathrm{CaAl}_{2} \mathrm{Si}_{2} \mathrm{O}_{8}(3 \% \mathrm{w} / \mathrm{w})$, and phyllosilicate mineral biotite $\left.\mathrm{K}^{+}(\mathrm{Mg}, \mathrm{Fe}) 3 \mathrm{AlSi} 3\right) \mathrm{O} 10(\mathrm{~F}, \mathrm{OH}) 2(1.5 \% \mathrm{w} / \mathrm{w})$. The growth columns were destructively sampled at 9 months, and investigated by the suite of imaging and analytical methods: (a) helium ion microscopy (Zeiss Orion PLUS) to characterize the mineral substrates colonization by microbes, and the opportunistic incorporation of the newly produced amorphous matter into the mineral structure. The advantage of HeIM was the remarkable depth of focus. (b) High-resolution scanning/transmission electron microscopy coupled with energy dispersive spectroscopy (EDAX), and selected area diffraction (FEI Titan 80-300 TEM). The instrument was operated in STEM mode, using High Angle Annular Dark Field (HAADF) detector, used for imaging and analyses of mineral edges identified as the prime target of microbial weathering. (c) Bulk soil crystallographic XRD techniques and X-ray computed tomography were used to characterize the mineral crystallinity and soil aggregation.

We hypothesized that during the cation-nutrient stress, the microbes would invest their energy into increased production of extracellular polymeric substances (EPS), in order to access and release the mineral cations as their sustenance needed for their metabolism. These microbial processes can include dissolution, precipitation and transformation of the mineral substrates, including redox and/or complexation reactions.

Although after the 9 months experiment we didn't find any indication of secondary minerals formation, we were able to determine the minerals crystallinity changes by increased fraction of amorphous material intercalated between the layers of biotite. 
This multi-scale, multi-capability approach enabled detailed investigation of the microbial-mineral weathering which includes release and uptake of $\mathrm{K}, \mathrm{Fe}, \mathrm{Mg}$ and $\mathrm{Al}$ at the microbial-mineral interface [3]. This knowledge will serve for a better understanding of soil minerals-microbial driven weathering process under nutrient-limited conditions.

\section{References:}

[1] Balogh-Brunstad, Z., C.K. Keller, R.A. Gill, B.T. Bormann, and C.Y. Li, 2008b. The effect of bacteria and fungi on chemical weathering and chemical denudation fluxes in pine growth experiments. Biogoechem. doi: 10.1007/s/10533-008-9202.

[2] Shi Z. Q., Z. Balogh-Brunstad, M. Grant, J. Harsh, R. Gill, L. Thomashow, A. Dohnalkova, D. Stacks, M. Letourneau, and C. K. Keller, 'Cation Uptake and Allocation by Red Pine Seedlings under Cation-Nutrient Stress in a Column Growth Experiment', Plant and Soil, 378 (2014), 83-98.

[3] S. Bonneville et al. / Geochimica et Cosmochimica Acta 75 (2011) 6988-7005.

[4] This research was performed at the Environmental Molecular Sciences Laboratory (EMSL), a national scientific sponsored by the Department of Energy's Office of Biological and Environmental Research, located at PNNL.
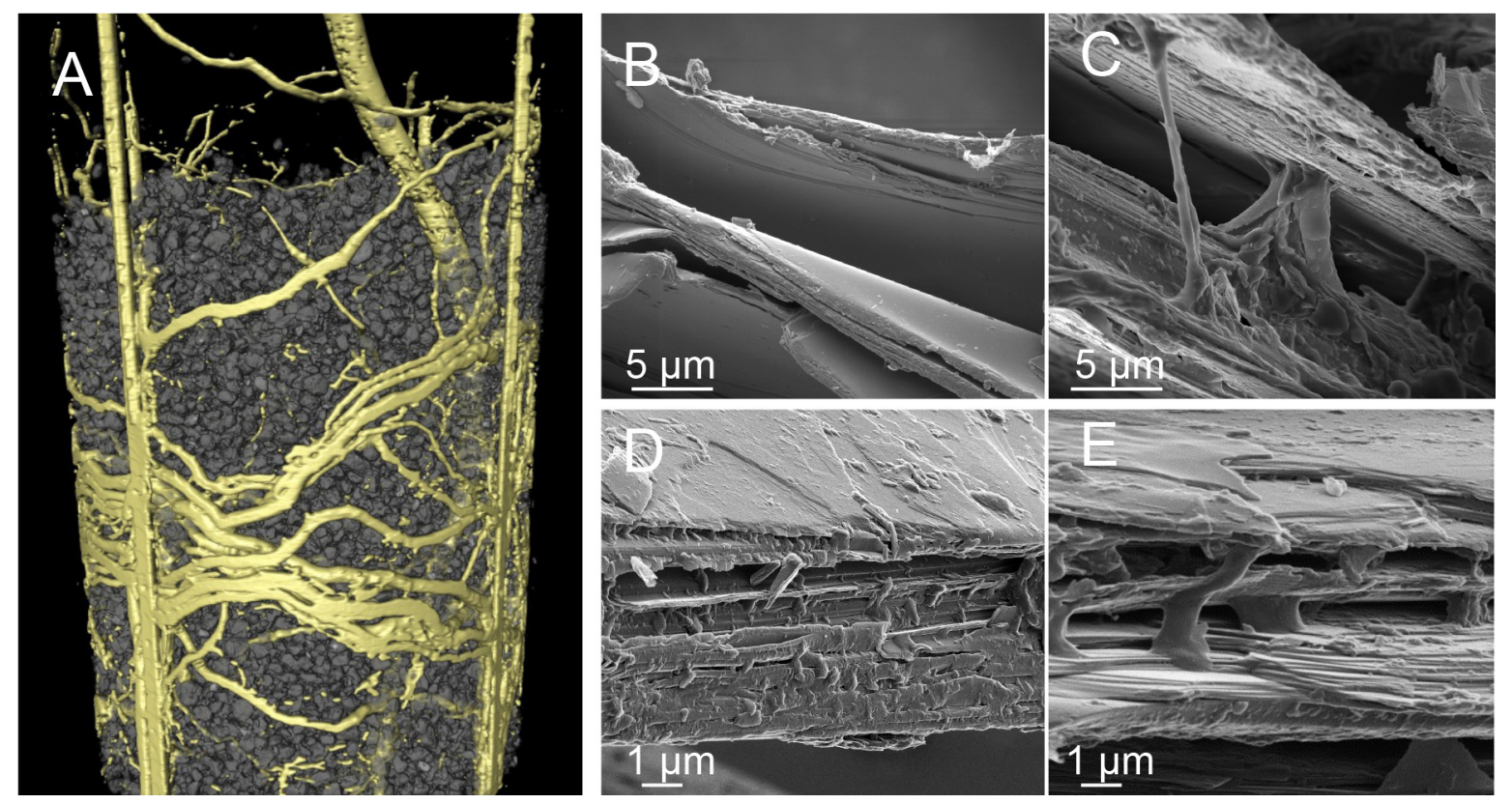

Figure 1. (A) X-ray computed tomography image of reconstructed column with tree roots and minerals reconstruction. Column diameter is $40 \mathrm{~mm}$. (B) Helium ion microscopy image of a biotite edge: the starting material without any organic residue. $(\mathrm{C}, \mathrm{D}, \mathrm{E})$ with freshly formed organic material that originated from the root exudates and microbial EPS. Notice the bacterially-produced amorphous organic material intercalated between the phyllosilicate layers, facilitating the mineral weathering. 